\title{
Higher Risk Does Bring Higher Returns in Stock Markets Worldwide
}

\author{
Hui Guo
}

$\mathbf{F}$ inancial market participants routinely use stock market volatility - that is, the size of fluctuations in stock returns-to gauge stock market risk. When riskaverse investors expect more stock market volatility, they reduce their stock holdings by selling stocks and buying safer assets, such as Treasury bills. This increase in demand for Treasury bills (relative to stocks) tends to raise current Treasury prices and reduce stock prices. Ultimately, a rise in expected stock volatility should raise the expected equity premium, which is the difference between the return on the stock market index and a risk-free rate.

The positive relation between expected stock market volatility and returns is a crucial building block of modern asset pricing theories: For a given level of stock market volatility, the more risk-averse investors are, the higher the expected equity premium must be for them to hold stocks in their portfolios.

Although researchers have intensively investigated this relation between expected stock market volatility and returns using both U.S. and international data, they have not firmly established evidence of a positive risk-return trade-off. That is, they have found no proof that higher risk results in higher returns; in fact, researchers usually estimate the risk-return trade-off to be economically very small or even negative.

A failure to control for other risk factors might explain the elusiveness of such evidence. One of these risk factors is the book-to-equity ratio, the ratio of the value of a firm's tangible assets (e.g., machinery, land) to that firm's market value. Stocks with high book-to-equity ratios (i.e., relatively low market values) tend to be risky investments, and investors require high expected returns for holding these stocks. This extra return is called the "value premium." Fama and French (1998) have shown

Risk-Return Trade-off Estimated by Guo et al. (2007)

\begin{tabular}{cccccccc} 
U.S. & Canada & France & Germany & Italy & Japan & U.K. & World \\
\hline $4.74^{* *}$ & 1.51 & $1.84^{*}$ & $1.88^{* *}$ & 0.65 & $1.90^{*}$ & $2.45^{* *}$ & $3.16^{* *}$
\end{tabular}

NOTE: *** indicate significance at the $10 / 5$ percent levels, which means that there is a $90 / 95$ percent likelihood these results did not occur by chance. 